\title{
Macrophage dysfunction in the pathogenesis and treatment of asthma
}

\author{
Michael Fricker ${ }^{1}$ and Peter G. Gibson ${ }^{1,2}$
}

Affiliations: ${ }^{1}$ NHMRC Centre of Excellence in Severe Asthma, Hunter Medical Research Institute, Priority Research Centre for Healthy Lungs, University of Newcastle, Newcastle, Australia. ${ }^{2}$ Dept of Respiratory and Sleep Medicine, John Hunter Hospital, Newcastle, Australia.

Correspondence: Michael Fricker, Hunter Medical Research Institute, University of Newcastle, Lot 1 Kookaburra Circuit, New Lambton Heights, NSW 2305, Australia. E-mail: michael.frickeranewcastle.edu.au

@ERSpublications

Lung macrophages display numerous, therapeutically targetable, context-specific dysfunctions in asthma http://ow.ly/g14430cQhp4

Cite this article as: Fricker M, Gibson PG. Macrophage dysfunction in the pathogenesis and treatment of asthma. Eur Respir J 2017; 50: 1700196 [https://doi.org/10.1183/13993003.00196-2017].

ABSTRACT Asthma is a chronic respiratory condition frequently associated with aberrant airway and systemic inflammation. Various inflammatory phenotypes in asthmatic airways have been described that relate to clinical phenotypes and impact on responses to conventional and novel asthma therapies. Macrophages are abundant immunocytes in the lung, capable of mounting diverse responses required for homeostasis and defence against pathogens.

Here, we summarise the clinical evidence regarding macrophage dysfunction in asthma. We also describe evidence supporting the role of macrophages as therapeutic targets in asthma. We conclude that macrophage dysfunction in asthma is highly prevalent and heterogeneous, and hypothesise that macrophages may play roles in promoting the discrete inflammatory phenotypes of asthma.

These clinical findings, along with recent ground-breaking insights into the ontogeny, behavioural complexity and longevity of pulmonary macrophages, support continued research into the role of macrophages as disease modifiers, biomarkers and therapeutic targets in asthma.

Received: Jan 272017 | Accepted after revision: June 112017

Support statement: Michael Fricker is supported by the National Health and Medical Research Council (NHMRC) Centre of Excellence for Severe Asthma. Peter G. Gibson is supported by a NHMRC practitioner fellowship. Funding information for this article has been deposited with the Crossref Funder Registry.

Conflict of interest: Disclosures can be found alongside this article at erj.ersjournals.com

Copyright @ERS 2017 


\section{Asthma and airway inflammation}

Asthma is a heterogeneous disease characterised by respiratory symptoms including shortness of breath, wheeze and chest tightness, which result from variable airflow limitation. Chronic airway inflammation is common and heterogeneous in asthma, and its characterisation is central to the development of effective and efficient personalised programmes of asthma care. In relation to this, airway inflammation has been proposed as one of the core "treatable traits" in chronic respiratory disease $[1,2]$. The emergence of targeted biological therapies has further stimulated research into asthma inflammatory phenotypes, which has proven critical for the success of recent clinical trials and in the identification of patients most likely to benefit from these relatively costly new treatments in the clinic [3].

Characterisation of airway inflammation has centred on identification and enumeration of discrete immune cell populations in the upper and lower airways [4]. Based on this quantification, patients may be classed into one of four inflammatory phenotypes of asthma: eosinophilic (high eosinophils, normal neutrophils), neutrophilic (normal eosinophils, high neutrophils), mixed granulocytic (high eosinophils, high neutrophils) and paucigranulocytic (normal eosinophils, normal neutrophils) [5]. While this system of phenotyping of asthma is of particular relevance in the context of this review, the burgeoning complexity of asthma phenotyping (based on clinical features and biomarkers) should be noted (for review, see $[6,7])$. Importantly these inflammatory phenotypes have value in predicting patient clinical phenotype and in guidance of pharmacological therapy $[6,8]$. In addition to eosinophils and neutrophils, numerous other cell types are present in asthmatic airways, including lymphocytes, mast cells and epithelial cells. The most abundant cells are often macrophages and monocytes, whose numbers remain relatively consistent between patients and across disease phenotypes [5].

Perhaps due to this limited fluctuation in macrophage numbers, there has been limited research into their potential role in asthma pathogenesis, as biomarkers and as targets for asthma therapy. Here, we summarise the existing research on macrophages in asthma from clinical studies, to examine their role as potential drug targets and in disease pathogenesis. We propose that rather than acting as passive bystanders to disease, diverse macrophage function/dysfunction may contribute to the varying inflammatory phenotypes of asthma.

\section{Macrophage function and ontogeny}

Macrophages are innate immune cells that possess numerous and diverse functions relating to their role as initial responders to immune stimuli and the development of the ensuing innate and adaptive immune response (figure 1). These functions include recognition, response to and destruction of invading microorganisms, antigen presentation, maintenance of tissue and immune homeostasis through removal of cellular debris, and production of inflammation modulating products. In addition, upon recognition of

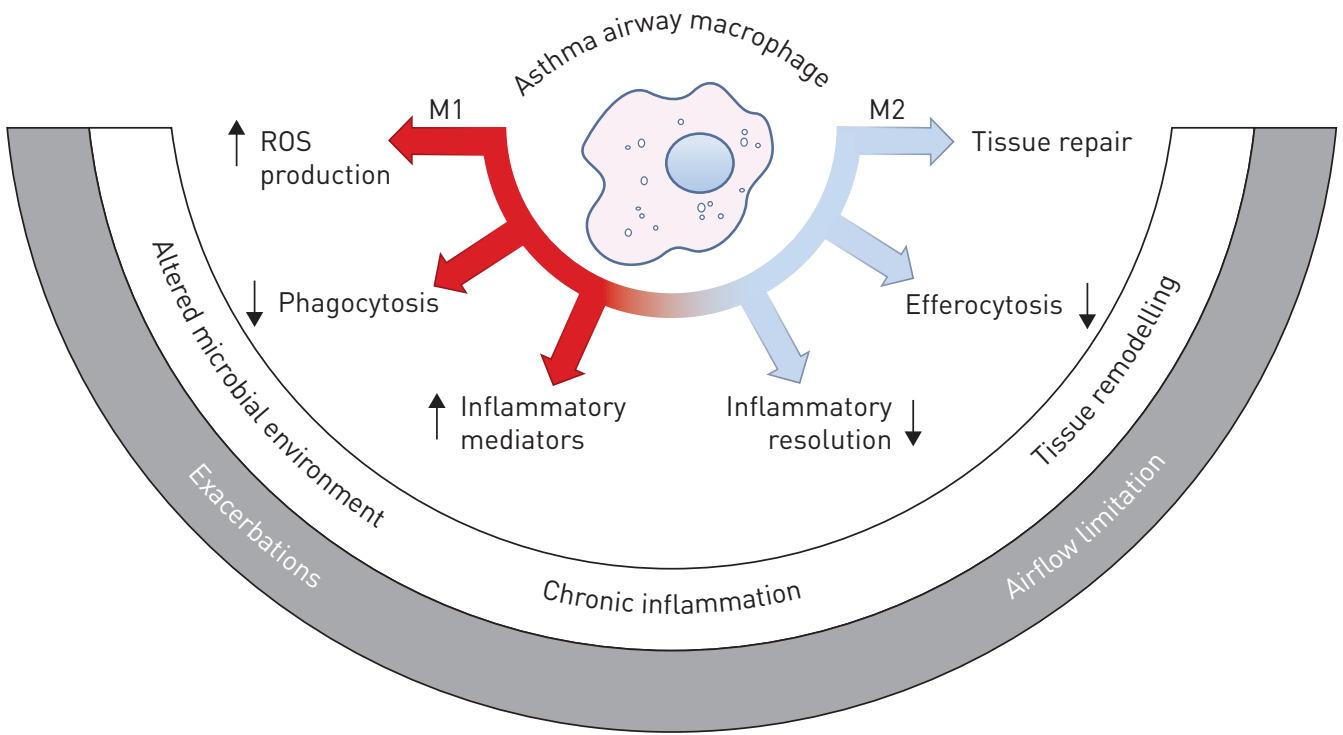

FIGURE 1 Macrophage dysfunction in asthma. Macrophages exert a variety of pro- and anti-inflammatory functions that are correlated with various states of immune activation and are broadly classed into M1- or M2-related classes. These important immune effector and homeostatic macrophage functions are altered in the asthmatic lung, and could contribute to and underpin discrete asthma pathologies and phenotypes. ROS: reactive oxygen species. 
inflammatory stimuli, macrophages are capable of mounting powerful (and potentially damaging) inflammatory responses.

The lung contains at least two distinct resident macrophage populations, and recent studies have informed a paradigm shift in our understanding of the ontogeny, maintenance and activation of discrete lung macrophage populations [9-11]. Alveolar macrophages reside in the airway lumen and are a relatively long-lived population. Alveolar macrophages were initially believed to be seeded and continually replenished from a pool of circulating monocytes; however, extensive cellular fate mapping in mice has revealed that the during fetal development the lung is first seeded with yolk-sac-derived macrophages, followed by fetal monocytes, the latter of which differentiate into and account for the majority of alveolar macrophages in the adult. In adulthood, the alveolar macrophages pool is maintained by proliferation in situ [12-15]. The literature surrounding interstitial macrophage longevity and origin is less clear, with evidence supporting both yolk-sac- and bone-marrow-derived interstitial macrophage populations, at least in mice (for review, see $[10,16]$ ). Like alveolar macrophages, interstitial macrophages appear capable of self-renewal through resident lung populations independently of infiltrating bone-marrow-derived monocytes. Little is known regarding macrophages residing in the bronchial lumen, and it remains unclear whether airway macrophages (isolated from bronchi using induced sputum) and alveolar macrophages (from bronchoalveolar lavage (BAL)) share a common ontogeny and function. The lung is also host to a resident monocyte population about which very little is known, other than they do not differentiate into alveolar macrophages and interstitial macrophages under normal conditions [9].

A further layer of complexity in the adult lung arises during inflammation and subsequent resolution of inflammation, as circulating monocytes are recruited to lung tissue and airways. These infiltrating monocytes possess unique functional roles and are also capable of differentiating under tissue-specific cues into alveolar macrophages that mimic resident embryonic-derived alveolar macrophage populations from a functional perspective [11]. Detailed transcriptomic analyses of bone-marrow-derived alveolar macrophages reveals differences in relatively few transcripts when compared with resident embryonic-derived alveolar macrophage populations, suggesting that although macrophage ontogeny contributes to macrophage phenotype within unique tissue microenvironments, tissue environmental-specific cues appear to play a dominant role [11, 17]. Differing origin and tissue-specific cues likely result in distinct functional output of alveolar macrophages, interstitial macrophages and pulmonary monocytes, with alveolar macrophages proposed to play a homeostatic suppressive innate immune role [18-20].

The distinct functions of subtypes of interstitial macrophages are poorly understood, and further work is also required to understand the potentially pathogenic roles of infiltrating monocytes and monocyte-derived macrophages. Of note, the recent advances in our understanding of pulmonary macrophage ontogeny stem largely from mouse studies, and further work will be required to define appropriate markers and means of monitoring and understanding the role of the various lung macrophage/ monocyte populations in the pathogenesis and treatment of asthma, in particular in clinical samples.

\section{Macrophage activation}

Macrophages have somewhat contradictory functional roles, with involvement in both pro- and anti-inflammatory processes. This behavioural diversity is largely dictated by ontogeny, tissue-derived cues (as discussed earlier) and exposure to ever-changing environmental stimuli. In general, pro-inflammatory innate immune functions have been ascribed to classically activated (or M1) macrophages, which arise following stimulation by pro-inflammatory molecules, including lipopolysaccharide (LPS), tumour necrosis factor (TNF)- $\alpha$ and interferon (IFN)- $\gamma$. In contrast, functions relating to parasite destruction, immune resolution and tissue remodelling are more pronounced in alternatively activated (or M2) macrophages, which can be elicited by type 2 cytokines (e.g. interleukin (IL)- 4 and IL-13). This classification is largely based on in vitro studies and recent in vivo work has shown that macrophages, including alveolar macrophages, exhibit a spectrum of activation states far more complex than this simple M1/M2 classification [21, 22]. Importantly, macrophages are capable of switching between these established and contrasting activation states, at least in vitro [23].

The key features of pulmonary macrophage biology (longevity, functional diversity and plasticity) highlight the potential for macrophage involvement in disease pathogenesis, and their utility as both biomarkers and drug targets in chronic inflammatory respiratory conditions, including asthma.

\section{Macrophage functions altered in asthma Phagocytosis}

Altered microbial colonisation of the airways is a feature of asthma. Inflammatory and clinical phenotypes of asthma are associated with distinct airway microbial signatures, although the causes and functional 
significance of airway dysbiosis in asthma remain unknown [24-28]. As abundant phagocytes, macrophages likely play a key role in shaping microbial diversity in the airways of asthmatic patients. Several clinical studies have established that macrophage phagocytosis is dysfunctional in asthma [22-30].

Defective phagocytosis of bacteria, yeast and carbon particulate matter has been demonstrated in alveolar macrophages and peripheral blood monocytes of asthmatic patients [22-30]. Severe asthma is associated with a defect in alveolar macrophage phagocytosis of the bacteria Haemophilus influenzae and Staphylococcus aureus, which are associated with airway dysbiosis in asthma [28, 29]. This defect in phagocytosis appears not to be limited to the airways, as monocyte-derived macrophages from severe asthmatic patients also exhibit deficient phagocytosis when compared with those derived from healthy and mild asthmatic patients. Treatment ex vivo with dexamethasone does not impair phagocytosis by monocyte-derived macrophages in any patient group, suggesting that defective phagocytosis observed in severe asthma alveolar macrophages is not due to high-dose corticosteroid treatment of these patients [30].

Similarly, in children, increasing asthma severity is associated with increased markers of oxidative stress and reduced bacterial phagocytosis in alveolar macrophages [31, 32]. Ex vivo supplementation with the antioxidant glutathione rescues alveolar macrophage phagocytosis, implicating oxidative stress as a potential contributor to impaired phagocytosis in severe asthma [31]. Alveolar macrophages from allergic asthmatic and aspirin-sensitive asthmatic patients display reduced phagocytosis of yeast zymosan bioparticles and production of associated effector molecules [33]. Phagocytosis of opsonised yeast by peripheral blood monocytes is impaired in asthmatic children, irrespective of asthma severity [34]. These defects in yeast bioparticle phagocytosis and downstream signalling are associated with the extent of BAL eosinophilia [33, 35]. The eicosanoid prostaglandin $\mathrm{E}_{2}\left(\mathrm{PGE}_{2}\right)$, which is elevated in the sputum of eosinophilic and severe asthma patients, has been linked to decreased phagocytosis of particulate carbon matter in airway macrophages of asthmatic children [36, 37].

To summarise, impaired macrophage phagocytosis of microbial and particulate matter is a feature of asthma. This impairment could contribute to the altered microbial environment and relate to bacterial-induced disease exacerbations, which characterise severe forms of asthma. Initial findings suggest that oxidant/antioxidant balance and the extracellular signalling milieu may play significant roles in the inhibition of macrophage phagocytosis in asthma. Importantly, these factors may be targeted for therapeutic gain.

\section{Efferocytosis}

Efferocytosis is the process by which dead, dying or stressed host cells are recognised, engulfed and digested by neighbouring cells. Macrophages are key mediators of efferocytosis, which plays a critical immune regulatory function. Rapid and efficient clearance of dying cells prevents or limits the release of damage-associated molecular patterns (DAMPs) and associated inflammation. Dead cells and DAMPs (e.g. high mobility group box 1) are elevated in asthmatic airways, consistent with a role for impaired efferocytosis in contributing to aberrant inflammation [38-40]. Importantly, efferocytosis is also a crucial mechanism for neutrophil turnover [41]. Thus, impaired efferocytosis could result in neutrophil persistence and contribute to the neutrophilic asthma phenotype. The efferocytotic capacity of macrophages of the upper and lower airways is reduced in asthma, particularly in individuals with noneosinophilic asthma [42-44].

Unique disease-related variables appear to have a significant impact on macrophage efferocytosis, with reduced efferocytosis observed in noneosinophilic versus eosinophilic asthma [42], obese versus nonobese asthma [43] and severe versus mild asthma [44]. It remains unclear whether impaired efferocytosis plays a role in promoting asthma pathology and symptoms. Further studies are required to elucidate the molecular mechanisms that underlie the efferocytosis defect in asthma, which could involve numerous receptors, bridging molecules and target molecules that mediate host cell recognition and uptake [41].

\section{Inflammatory mediator production}

In the airway lumen and bronchial mucosa, macrophages are major cellular sources of critical pro-inflammatory cytokines, including TNF- $\alpha$, IL-1 $\beta$, IL-6 and IL-8 $[45,46]$. Alveolar macrophages from asthmatic patients release more TNF- $\alpha$, IL-1 $\beta$, IL-6 and IL-8 than healthy controls, but display a dampened inflammatory response to LPS stimulation. In contrast to healthy alveolar macrophages, IL-4 treatment fails to significantly inhibit LPS-induced pro-inflammatory cytokine release in asthmatic alveolar macrophages [47-51]. The innate pro-inflammatory TNF- $\alpha$ and IL-1 $\beta$ signalling pathways are implicated in neutrophilic asthma [52]. This correlates with increased IL-1 $\beta$ production by airway macrophages in asthma [53], in particular neutrophilic asthma [54]. 
In addition to the airway lumen, macrophages and monocytes appear to be a significant source of increased TNF- $\alpha$ and IL-1 $\beta$ in asthmatic airway tissue and the bronchial epithelium [46, 55]. IL-17 is a key pro-inflammatory cytokine of the T-helper 17 (Th17) cell pathway and has been linked to a role in promoting neutrophilic airway inflammation in asthma [56]. Although Th17 cells are a major cellular source of IL-17, other immune cell types have been implicated in its production in asthma [57]. IL-17 is elevated in the BAL of asthmatic patients, which correlates with increased numbers of IL-17 $7^{+}$alveolar macrophages [58]. In addition, evidence suggests that alveolar macrophages play an important role in the late-phase inflammatory response of atopic asthmatic patients following allergen challenge, producing increased TNF- $\alpha$ and IL-6 [59].

The possible roles of macrophages in influencing varying adaptive immunity pathways in the asthmatic lung remain relatively unexplored. Of note, the enhanced production of IL-1 $\beta$ and IL- 6 by asthmatic alveolar macrophages can drive increased IL- 5 production by $\mathrm{CD}^{+}$T-cells, potentially enhancing eosinophilic inflammation in the airways of asthmatic patients [60].

To summarise, altered pro-inflammatory cytokine production by pulmonary macrophages likely contributes to chronic airway inflammation. Importantly, macrophages may adopt differing phenotypes in discrete inflammatory subsets of asthma.

\section{Anti-inflammatory molecule production}

IL-10 is a critical anti-inflammatory cytokine and is thought to be an important mediator of macrophage anti-inflammatory functions in the resolution of inflammation. IL-10 protein levels are decreased in the airways of asthmatic patients [61]. However, studies on airway macrophages have reached conflicting conclusions. While IL-10 mRNA is increased in alveolar macrophages and sputum macrophages [62-64], protein expression in macrophages is decreased [65-67], suggesting altered post-transcriptional or post-translational regulation of IL-10 in asthma alveolar macrophages. IL-12 expression is reduced and could contribute to the enhanced Th2-skewing activity displayed by alveolar macrophages from asthmatic patients versus healthy patients and associated enhanced IL-5 production from CD ${ }^{+} \mathrm{T}$-cells $[51,68]$.

Transforming growth factor (TGF)- $\beta$ is a pleiotropic cytokine produced by multiple cell types in the inflamed lung. TGF- $\beta$ levels are increased in both the airways and mucosal tissue of asthmatic patients [69, 70]. Although TGF- $\beta$ mRNA is increased in alveolar macrophages of asthmatic patients [64], considerable regulation occurs at the post-translational level and protein production by alveolar macrophages has not been explored. Mucosal expression appears largely limited to eosinophils, neutrophils and fibroblasts [70, 71].

Numerous studies have established that the balance between production of pro-inflammatory lipid mediators leukotrienes and anti-inflammatory lipoxins is disturbed in asthma. In particular, severe asthma in adults and children is associated with an increased leukotriene $\mathrm{B}_{4}\left(\mathrm{LTB}_{4}\right) /$ lipoxin $\mathrm{A}_{4}\left(\mathrm{LXA}_{4}\right)$ ratio, measurable both in the airways and on a systemic level [72-75]. Macrophages appear to be a critical cellular site of impaired lipoxin synthesis in severe asthma [72], which is associated with increased oxidative stress and can be reversed by inhibitors of soluble epoxide hydrolase [76]. How this balance of macrophage eicosanoid synthesis is perturbed in different inflammatory phenotypes of asthma is unknown at present; however, the measurement of the $\mathrm{LTB}_{4} / \mathrm{LXA}_{4}$ ratio in exhaled breath condensate may present a good opportunity for the development of a clinically useful biomarker [77].

\section{Altered macrophage polarisation in asthma}

Few clinical studies have addressed the relative abundance or role of M1 and M2 macrophages in asthma pathogenesis (reviewed by JIANG and ZHU [78]). Recent studies have indicated that M2 macrophages may be elevated in asthma based on marker molecule expression $[79,80]$. The clinical studies described in the previous sections, however, indicate that a number of M1- and M2-related functions of macrophages are altered in asthma (figure 1). As recent studies indicate, macrophage activation and polarisation is immensely complex. Transcriptional analyses provide expanded frameworks to examine the reprogramming of airway macrophages in asthma [22, 81]. Given the plasticity and complexity of macrophage phenotypes in the lung in vivo, further comprehensive studies of macrophage polarisation in stable and exacerbating asthma would be of value.

\section{Modulation of macrophage function by asthma therapies Corticosteroids}

Corticosteroids are one of the most commonly prescribed medications for the treatment of asthma. Corticosteroids exert anti-inflammatory effects and may target multiple cell types in asthma, including epithelial and immune cells [82], although macrophages are proposed to be one of the principle targets [83]. In asthma, corticosteroid stimulation of alveolar macrophages induces glucocorticoid receptor- $\alpha$ 
translocation to the nucleus and subsequent recruitment of histone deacetylases (HDACs) to target promoter sequences, often resulting in suppression of pro-inflammatory genes [83-85].

Effects of corticosteroids on macrophages in asthma

Numerous clinical trials have shown that treatment of asthmatic patients with corticosteroids can modulate airway macrophage functions (table 1). Corticosteroid treatment of asthma patients suppresses $\mathrm{PGE}_{2}$ and $\mathrm{LTB}_{4}$ production by alveolar macrophages [86-88]. A single dose of prednisone can suppress alveolar macrophage-mediated IL-1 $\beta$ production in the lower airways of asthmatic patients [53], and corticosteroids can reduce LPS-induced TNF- $\alpha$, IL-1 $\beta$, IL-6 and IL-8 to varying extents [84, 89, 90]. Corticosteroids may also function through enhancement of anti-inflammatory functions of alveolar macrophages, including IL-10 synthesis [66, 91]. Corticosteroids reduce oxidative stress in asthmatic airways through reduction of alveolar macrophage reactive oxygen species (ROS) formation [92]. Alveolar macrophage expression of the oxidative stress marker haem oxygenase- 1 is increased in steroid-naive asthma and suppressed by corticosteroid treatment $[93,94]$.

\section{Corticosteroid resistance in asthmatic macrophages}

Responses to corticosteroids vary among asthma patients and individuals with severe asthma often respond poorly to corticosteroid treatment. Several clinical studies have shown that relative resistance of clinical features of asthma to corticosteroid treatment correlates with relative corticosteroid resistance of alveolar macrophages. This alveolar macrophage resistance manifests as reduced capacity of corticosteroids to suppress LPS-induced pro-inflammatory $\mathrm{LTB}_{4}$, TNF- $\alpha$, IL-6, IL-1 $\beta$ and CXCL8 production [84, 95-97]. Alveolar macrophage inflammatory function is skewed towards an M1-like phenotype in corticosteroid-resistant asthmatic patients, which is associated with higher BAL endotoxin levels and altered microbial colonisation of the airways $[27,98]$.

Although a role for an altered airway microbiome has been proposed in the development of corticosteroid resistance in asthmatic alveolar macrophages [27], the finding that circulating monocytes of severe asthmatic patients also display corticosteroid resistance may challenge this hypothesis [99]. Corticosteroid resistance in asthmatic alveolar macrophages correlates with activation of the p38 signalling pathway [96] and p38 inhibitors can restore corticosteroid sensitivity to severe asthma alveolar macrophages ex vivo [95, 100]. Aberrant p38 pathway activity may drive corticosteroid resistance through phosphorylation and inhibition of glucocorticoid receptor- $\alpha$, although upregulation of the inhibitory glucocorticoid receptor- $\beta$ isoform in asthma alveolar macrophages may also play a role [84]. Of note, it has been suggested that the association of alveolar macrophage glucocorticoid insensitivity with clinical corticosteroid insensitivity could be used to guide pharmacotherapy [95].

To summarise, several clinical studies point towards the alveolar macrophages as a critical cellular site of corticosteroid resistance in severe forms of asthma.

\section{Macrolides}

Macrolide treatment has been associated with improved asthma outcomes for $>40$ years [101, 102]. Although used primarily as antibiotics, studies have established that macrolides possess additional immunomodulatory properties, a combination of which may render them particularly effective in asthma. Those asthma subtypes most likely to benefit from macrolide treatment include severe noneosinophilic asthma [103, 104], asthmatic patients that test positive for the presence of Mycoplasma pneumoniae and Chlamydia pneumoniae [105-107], and eosinophilic aspirin-sensitive asthma [108].

It remains unclear whether macrolides exert protective effects primarily through their antibacterial properties or whether immunomodulatory effects of macrolides on immune cells are required. The utility of this approach as a long-term therapy for asthma is an issue, given concerns about the emergence of bacterial resistance. The development of macrolides lacking antibiotic activity but retaining their immunomodulatory effects may help to address this $[109,110]$. Of note, azithromycin treatment of both azithromycin-resistant and -susceptible pneumococci reduced TNF- $\alpha$ production in bacteria-exposed macrophage cells, providing evidence that antibacterial activities are not required for immunomodulation of macrophage function [111].

\section{Effects of macrolides on macrophages}

Clinical trials have confirmed immunomodulatory functions of macrolides in asthma, including reduction of cytokine expression (IL-8, TNF- $\alpha$ and IL-12) typically associated with macrophages (table 1) [103, 106]. Macrolides accumulate within the lysosomes of phagocytic cells, reaching concentrations far higher than those measured in extracellular compartments. In the lung, macrophages and neutrophils accumulate 


\begin{tabular}{|c|c|c|c|}
\hline Drug & $\begin{array}{l}\text { Asthmatic group } \\
\text { tested }\end{array}$ & Inflammatory outcome & Reference \\
\hline \multicolumn{4}{|l|}{ Corticosteroids } \\
\hline Prednisone & $\begin{array}{l}\text { Mild, atopic, } \\
\text { nocturnal }\end{array}$ & $\begin{array}{c}\downarrow \text { Airway neutrophilia; } \downarrow \text { alveolar } \\
\text { macrophage } \mathrm{LTB}_{4}\end{array}$ & [87] \\
\hline Prednisone/deflazacort & Mild, uncontrolled & $\downarrow \mathrm{BAL} \mathrm{LTB}_{4}$ and $\mathrm{PGE}_{2}$ production & [86] \\
\hline Prednisone & Atopic & $\begin{array}{c}\downarrow \text { Ex vivo alveolar macrophage } \mathrm{LTB}_{4} \\
\text { production }\end{array}$ & [88] \\
\hline Budesonide & Mild, atopic & $\begin{array}{l}\uparrow \text { Alveolar macrophage IL- } 10 ; \downarrow \text { alveolar } \\
\text { macrophage MIP- } 1 \alpha \text {, IFN- } \gamma \text { and GM-CSF }\end{array}$ & [66] \\
\hline ICS or ICS+LABA & Mild-to-moderate & $\begin{array}{l}\uparrow \text { Sputum IDO activity correlating with } \\
\uparrow \text { macrophage IL-10 production }\end{array}$ & [91] \\
\hline Prednisone & Mild & $\downarrow$ Alveolar macrophage IL- $1 \beta$ production & [53] \\
\hline Beclomethasone & Uncontrolled & $\begin{array}{l}\downarrow \text { BAL eosinophil and mast cell count; } \\
\downarrow \text { alveolar macrophage ROS correlated } \\
\text { with improved airway hyperreactivity }\end{array}$ & [92] \\
\hline \multicolumn{4}{|l|}{ Macrolides } \\
\hline Clarithromycin & Severe, refractory & $\downarrow$ Sputum IL-8 and neutrophilia & [103] \\
\hline Azithromycin & Severe, FENO normal & No alteration in FENO & [104] \\
\hline Clarithromycin & Moderate & $\begin{array}{c}\downarrow T N F-\alpha \text { and IL- } 12 \text { in BAL and airway } \\
\text { tissue }\end{array}$ & [106] \\
\hline Clarithromycin & Mild-to-moderate & No alteration in FENO & [107] \\
\hline \multicolumn{4}{|l|}{ Statins } \\
\hline Simvastatin & Mild-to-moderate & $\begin{array}{l}\text { No effect on airway and blood } \\
\text { eosinophilia }\end{array}$ & [174] \\
\hline Simvastatin & $\begin{array}{l}\text { Mild-to-moderate, } \\
\text { eosinophilic }\end{array}$ & $\begin{array}{c}\downarrow \text { Sputum eosinophilia in subgroup of } \\
\text { patients }\end{array}$ & [175] \\
\hline Atorvastatin & $\begin{array}{l}\text { Mild-to-moderate, } \\
\text { atopic }\end{array}$ & $\begin{array}{c}\downarrow \text { Sputum macrophage numbers and } \\
\mathrm{LTB}_{4} \text { production }\end{array}$ & [130] \\
\hline Simvastatin & Mild & $\begin{array}{l}\uparrow \text { Sputum macrophage IDO activity and } \\
\text { sputum IL-10; } \downarrow \text { sputum eosinophilia }\end{array}$ & [129] \\
\hline Atorvastatin & Smokers & $\begin{array}{c}\text { No change in sputum cell counts or } \\
\text { cytokine levels }\end{array}$ & [176] \\
\hline Atorvastatin & $\begin{array}{l}\text { Mild-to-moderate, } \\
\text { smokers }\end{array}$ & $\downarrow$ Sputum cytokine levels & [132] \\
\hline \multicolumn{4}{|l|}{$\begin{array}{l}\text { Phosphodiesterase } \\
\text { inhibitors }\end{array}$} \\
\hline Theophylline & $\begin{array}{l}\text { Atopic with allergen } \\
\text { challenge }\end{array}$ & $\downarrow$ Airway tissue eosinophils & [177] \\
\hline Theophylline & Mild & $\downarrow$ Airway eosinophilia & [178] \\
\hline Theophylline & Mild & $\begin{array}{c}\downarrow \text { Sputum macrophage } \mathrm{LTB}_{4} \text { production } \\
\text { and neutrophilia }\end{array}$ & [139] \\
\hline Theophylline & Severe & $\begin{array}{l}\text { Theophylline withdrawal led to } \\
\uparrow \text { monocytes and lymphocytes in airways }\end{array}$ & [179] \\
\hline Theophylline & Mild & $\uparrow$ HDAC activity in bronchial biopsy & [138] \\
\hline Roflumilast & Mild, atopic & $\begin{array}{l}\downarrow \text { Late asthmatic reaction linked to } \\
\text { inflammation }\end{array}$ & [149] \\
\hline Roflumilast & Mild, atopic & $\begin{array}{l}\downarrow \text { Allergen-induced sputum eosinophilia } \\
\text { and neutrophilia }\end{array}$ & [151] \\
\hline
\end{tabular}

$\mathrm{LTB}_{4}$ : leukotriene $\mathrm{B}_{4}$; BAL: bronchoalveolar lavage; $\mathrm{PGE}_{2}$ : prostaglandin $\mathrm{E}_{2}$; IL: interleukin; MIP: macrophage inflammatory protein; IFN: interferon; GM-CSF: granulocyte-macrophage colony-stimulating factor; ICS: inhaled corticosteroid; LABA: long-acting $\beta$-agonist; IDO: indoleamine 2,3-dioxygenase; ROS: reactive oxygen species; FENO: exhaled nitric oxide fraction; TNF: tumour necrosis factor; HDAC: histone deacetylase.

macrolides to the greatest extent and maintain high intracellular concentrations long after treatment, and thus could represent important cellular sites of immunomodulatory function in asthma [112-115].

Treatment of acutely exacerbating asthmatic children with clarithromycin reduced concentrations of macrophage-associated cytokines TNF- $\alpha$, IL-1 $\beta$ and IL-10 in nasopharyngeal aspirates [116]. Macrolides can reduce airway IL- $1 \beta$ and TNF- $\alpha$ and alveolar macrophage IL- 8 in patients with chronic lower respiratory tract infection, supporting suppression of M1 macrophage-related mediators as a mechanism of 
macrolide action in the lung [117]. Macrolide suppression of IL-8 production in alveolar macrophages was confirmed in a separate study [118]. These clinical studies are supported by numerous studies performed on isolated macrophages and macrophage cell lines in vitro [119].

Macrolide treatment also has impacts on macrophage phagocytosis and efferocytosis. Erythromycin and clarithromycin treatment enhance efferocytosis of apoptotic neutrophils by healthy human alveolar macrophages, independently of pro-inflammatory mediator production [120].

Although not studied in asthma, defective efferocytosis of alveolar macrophages from chronic obstructive pulmonary disease (COPD) patients was restored back to levels seen in healthy patients with azithromycin treatment both ex vivo and in vivo $[121,122]$. In addition, azithromycin treatment of COPD patients improved bacterial phagocytosis by alveolar macrophages [123], although ex vivo azithromycin treatment only improved defective phagocytosis in monocyte-derived macrophages derived from smokers but not COPD patients [124]. Thus, macrolide treatment can rescue defective efferocytotic and phagocytic activity displayed by alveolar macrophages in COPD. As alveolar macrophages in severe and noneosinophilic asthmatic patients display similar defects in efferocytosis as those of COPD patients, it is plausible that macrolide treatment could exert similar effects in asthma. At present the mechanisms underlying macrolide-mediated rescue of defective alveolar macrophages efferocytosis are unknown [122].

\section{Statins}

Statins (5-hydroxy-3-methylglutaryl-coenzyme A (HMG-CoA) reductase inhibitors) are widely prescribed cholesterol-lowering drugs. Statins have also been widely reported to exert immunomodulatory effects, including anti-inflammatory effects. Statin use is associated with reduced severe asthma exacerbation-related hospital and emergency department visits [125-127]. Given the link between airway inflammation and asthma exacerbation frequency [128], this suggests statins may at least in part act through anti-inflammatory mechanisms. Indeed, several clinical trials, while failing to show improvements in lung function, have demonstrated anti-inflammatory effects of statins in asthma (table 1).

\section{Effects of statins on macrophages}

Statin treatment in asthmatic patients enhances inhaled corticosteroid (ICS)-induced activation of the noncanonical NF- $\mathrm{BB}$ pathway in alveolar macrophages, resulting in enhanced indoleamine 2,3-dioxygenase transcription and enzymatic activity, which stimulates IL-10 production [129]. A separate clinical trial concluded that statin treatment reduces sputum macrophage counts and $\mathrm{LTB}_{4}$ levels [130]. Of note, a combination of ICS and atorvastatin treatment in smoking asthmatic patients significantly reduces sputum IL-1 $\beta$, a cytokine produced by macrophages and neutrophils and linked to neutrophilic asthma phenotypes [131]. Thus, it is possible that statin treatment may benefit subsets of asthmatic patients with corticosteroid-insensitive inflammation, such as that associated with smoking and neutrophilic airway inflammation [132].

In alveolar macrophages isolated from COPD patients lovastatin restores defective efferocytosis in an HMG-CoA reductase-dependent manner [133]. As similar alveolar macrophage efferocytosis defects exist in severe and neutrophilic asthma, further clinical trials examining this potential therapeutic mechanism of statins are merited $[42,122]$. Statins also exert anti-inflammatory effects in rhinovirus-infected asthmatic alveolar macrophages, implicating cholesterol biosynthesis in the macrophage antiviral response [134]. Atorvastatin inhibits the particulate-induced production of a number of critical innate immune mediators in alveolar macrophages, including IL-1 $\beta$, granulocyte-macrophage colony-stimulating factor (GM-CSF), IL- 6 and TNF- $\alpha$. In contrast, pro-inflammatory cytokine production by primary bronchial epithelial cells induced by particulate matter is unaffected, supporting the role of macrophages as an important site of statin-mediated immunomodulation in the lung [135].

A recent large-scale screen of drugs in clinical use on macrophages identified statins as enhancing tetraspanin expression, which inhibits LPS-mediated inflammatory signalling through sequestration of the LPS signalling mediator CD14 [136]. This finding may have particular relevance in noneosinophilic asthma, which is associated with abnormal Toll-like receptor signalling and enhanced bacterial colonisation of the airways.

To summarise, mechanistic studies have demonstrated a number of mechanisms whereby statins suppress inflammation in lung macrophages, pointing towards promising avenues of research and highlighting potential asthmatic populations that may benefit most from statin treatment (e.g. frequent exacerbators, obese asthmatic patients, neutrophilic asthmatic patients and patients with airway dysbiosis).

\section{Phosphodiesterase inhibitors}

\section{Theophylline}

Theophylline has been used for the treatment of asthma for almost a century [137]. Theophylline was initially prescribed as a bronchodilator, although unfavourable side-effects associated with the doses 
required to achieve bronchodilation have seen it superseded and largely replaced by $\beta$-agonists. Theophylline exerts its biological effects through inhibition of phosphodiesterases (PDEs), including PDE-3 and PDE-4 isoforms, increasing intracellular concentrations of the second messenger molecules cAMP and cGMP. While PDE-3 inhibition is related to bronchodilatory effects, PDE-4 inhibition is strongly linked to immunomodulatory functions. Side-effects associated with theophylline, including nausea and headaches, also result from PDE inhibition.

Several clinical trials of theophylline in asthma have assessed the use of low doses, which maintain the anti-inflammatory effects while reducing side-effects (and bronchodilation) (table 1). These studies have demonstrated efficacy of low-dose theophylline as a steroid-sparing agent in mild-to-moderate asthma and beneficial effects in relatively corticosteroid-refractory patients who smoke or have severe asthma.

\section{Effects of theophylline on macrophages}

The corticosteroid-sparing effects of theophylline may involve induction of HDAC activity in alveolar macrophages [138]. Corticosteroids exert their anti-inflammatory effects, in part, by mediating recruitment of HDACs to pro-inflammatory gene promoter sequences, resulting in deacetylation and transcriptional suppression. Theophylline treatment of mild asthmatic patients increases HDAC activity and expression in bronchial biopsies [138]. In addition, alveolar macrophages from mild asthmatic patients display similar increases in HDAC activity in response to low-dose dexamethasone combined with theophylline versus high-dose dexamethasone alone. Theophylline alone is sufficient to increase HDAC activity, allowing greater suppression of inflammation when corticosteroids are added and synergistic inhibition of pro-inflammatory gene expression $[85,138]$.

Further studies have substantiated the role of macrophages as key targets for the immunomodulatory effects of theophylline in asthma. Alveolar macrophages isolated from mild asthmatic patients treated with theophylline have reduced pro-inflammatory $\mathrm{LTB}_{4}$ production and thus theophylline can reduce pro-inflammatory eicosanoid production by alveolar macrophages in vivo [139]. Theophylline also inhibits TNF- $\alpha$ and enhances IL-10 production in LPS-stimulated peripheral blood mononuclear cells isolated from asthmatic patients [140]. In addition, theophylline treatment of alveolar macrophages ex vivo inhibits zymosan-stimulated cAMP degradation and hydrogen peroxide generation [141].

While these studies demonstrated anti-inflammatory actions of theophylline on macrophages, most only reported effects following receipt of an exogenous pro-inflammatory stimulus. Of note, primary alveolar macrophages isolated directly from theophylline-treated mild asthmatic patients exhibit no change in baseline production of IL-10, GM-CSF or TNF- $\alpha$, although eosinophil levels are reduced in the BAL of these patients [142]. Thus, while theophylline can inhibit baseline inflammatory characteristics of monocytes and alveolar macrophages when administered ex vivo [143, 144], it is likely that immunomodulatory targets additional to macrophages are also important in the clinic. A limitation of these studies is that they have largely reported on a limited range of potential pro-inflammatory outputs of macrophages. A transcriptomic approach revealed that theophylline exerts broad effects, highlighting the potential of theophylline to inhibit a number of alternative pro-inflammatory pathways, including the production of IL-13 [145]. Therefore, theophylline may inhibit both type 1 and type 2 cytokine production in alveolar macrophages, establishing a link to eosinophilic asthmatic subtypes that merits further exploration.

\section{Roflumilast}

Roflumilast is a potent selective PDE-4 inhibitor, which is thought to exert its anti-inflammatory action through inhibition of the PDE-4B isoform [146]. It is approved for the treatment of COPD and asthma. Clinical trials of roflumilast in asthma have established that it provides similar benefits to low/ moderate-dose ICS treatment, assessed by improvement in lung function, asthma symptoms and reduced rescuer use (table 1) [147, 148]. In addition, several clinical trials have shown that short-term (up to 14 days of treatment) roflumilast dosing can inhibit both early and late asthmatic responses to allergen [149-151]. Roflumilast appears to be particularly effective at reducing the late asthmatic response, reducing allergen-induced sputum eosinophil and neutrophil influx, and associated inflammatory biomarkers in asthmatic individuals $[151,152]$.

\section{Effects of roflumilast on macrophages}

Macrophages express a number of PDE-4 isoforms, with PDE-4B being the principle target of roflumilast [153]. Roflumilast is anti-inflammatory in primary human lung macrophages, inhibiting LPS-stimulated release of pro-inflammatory chemokines and cytokines in a cyclooxygenase-2-dependent manner, via production of $\mathrm{PGE}_{2}$ [154]. Further studies are required to fully elucidate the critical cellular sites of 
anti-inflammatory roflumilast activity in asthma; however, based on current evidence, macrophages remain plausible candidate targets.

\section{Leukotriene antagonists}

The leukotriene signalling pathway is a target of several therapeutics used in maintenance therapy of asthma [155]. Leukotriene signalling is targeted in the clinic through use of cysteinyl leukotriene receptor antagonists (e.g. montelukast and zafirlukast) and inhibition of 5-lipoxygenase (zileuton), an enzyme involved in both cysteinyl leukotriene and $\mathrm{LTB}_{4}$ production. Antagonists of this pathway exert both bronchodilatory and anti-inflammatory effects.

\section{Effects of leukotriene antagonism on macrophages}

Alveolar macrophages both produce and respond to cysteinyl leukotrienes and $\mathrm{LTB}_{4}$, and the balance between these pro-inflammatory factors and anti-inflammatory mediators such as $\mathrm{LXA}_{4}$ is disturbed in asthma (as discussed earlier). In addition, monocytes, along with eosinophils, epithelial cells and airway smooth muscle cells, express cysteinyl leukotriene receptor.

Zileuton inhibits cysteinyl leukotriene and $\mathrm{LTB}_{4}$ production in stimulated alveolar macrophages as well as in other immunocytes, including eosinophils, neutrophils and mast cells [156-158]. Although it has been suggested that macrophages may indeed be an important therapeutic target of leukotriene antagonists [159], convincing clinical evidence is lacking.

Montelukast treatment of atopic asthmatic children reduces systemic TNF- $\alpha$, which may be in part mediated by the inhibition of leukotriene signalling in monocytes [160]. The action of cysteinyl leukotriene on monocytes/macrophages results in increased migration, ROS production, release of matrix metalloproteinase-9 and production of pro-inflammatory cytokines [161]. Additionally, montelukast treatment of M2-polarised blood monocytes prevented LPS-induced upregulation of M2-associated cytokines, including IL-10 [162].

To summarise, leukotriene antagonists modulate numerous macrophage and monocyte functions relevant in the context of asthma. However, numerous cellular targets for these agents exist and further high-quality clinical evidence would be required to confirm a role of macrophages as therapeutic targets of leukotriene antagonists. Additional questions regarding the action of leukotriene antagonists on macrophages in asthma remain, such as whether the observed inhibitory effect on macrophage phagocytosis via the Fc receptor has clinical relevance [163] and whether variable macrophage phenotypes may underlie the differential response of atopic asthmatic patients to leukotriene antagonism in allergen challenge models [159].

\section{$\boldsymbol{\beta}$-Agonists}

$\beta$-Agonists act as bronchodilators, acting principally to induce relaxation of airway smooth muscle. Short-acting $\beta$-agonists (SABAs) are a mainstay of asthma therapy, and are often prescribed as monotherapy in mild asthma or are used as reliever medications during periods of asthma exacerbation in mild and severe asthmatic patients [164]. Long-acting $\beta$-agonists (LABAs) are also widely prescribed as a therapeutic add-on to ICSs, the use of which largely negates the negative health impacts of LABAs [164, 165]. In addition to their bronchodilatory action on airway smooth muscle, $\beta$-agonists exert anti-inflammatory effects through numerous targets including eosinophils, T-lymphocytes, neutrophils and mast cells [166].

\section{Effects of $\beta$-agonists on macrophages}

Several studies have demonstrated the presence of $\beta_{2}$-adrenergic receptors on alveolar macrophages [167] and their responsiveness to $\beta$-agonist stimulation $[168,169]$. However, repeated use of $\beta$-agonists reduces surface $\beta_{2}$-adrenergic receptor expression in lung macrophages and desensitises to further $\beta$-agonist stimulation $[168,170]$. This phenomenon is also observed in other cell types, where it is reversible by concomitant treatment with corticosteroids. However, reversibility following corticosteroids treatment does not occur in alveolar macrophages [171]. Thus, lung macrophages in asthmatic patients on frequent SABA or LABA treatment are unlikely to respond strongly to $\beta$-agonist. Ex vivo stimulation of alveolar macrophages with opsonised zymosan or IgE/anti-IgE complexes induced inflammatory mediator production that was not inhibited by isoprenaline treatment. However, salbutamol treatment could suppress $\mathrm{LTB}_{4}$ production under the same conditions $[172,173]$.

To summarise, macrophages would not appear to be an important cellular target for bronchodilator and immunomodulator functions of $\beta$-agonists. 


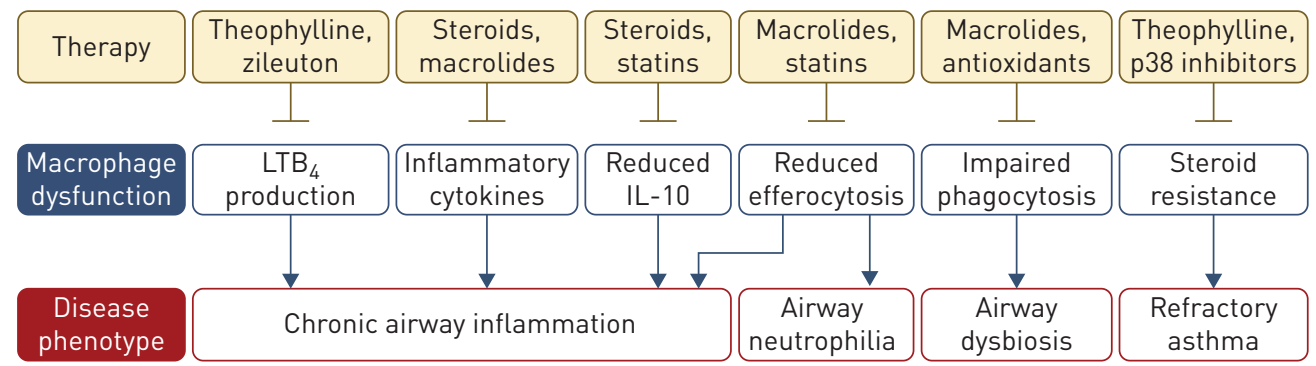

FIGURE 2 Therapeutic targeting of macrophage dysfunction in asthma. A number of commonly prescribed therapies may beneficially modulate macrophage function in asthma. $\mathrm{LTB}_{4}$ : leukotriene $\mathrm{B}_{4}$; IL: interleukin.

\section{Conclusions and suggestion of knowledge gaps}

Macrophages carry out a range of essential immune functions in the lungs and these functions are dysregulated in asthma. Preliminary evidence from clinical trials suggests that a number of macrophage functions may be targeted using conventional and novel treatments, and that targeting of macrophage (dys)function in asthma may form part of the therapeutic mechanism of action (figure 2). The description of hitherto underappreciated functional complexity and plasticity of macrophage phenotypes has highlighted a knowledge gap regarding the roles of macrophages in the pathogenesis of asthma. A few recent studies have begun to reveal that, much like asthma, macrophage dysfunction in asthma is heterogeneous, further strengthening the argument for their involvement as pivotal disease modulators.

The recent paradigm shift in our understanding of the ontogeny and activation of various macrophage populations within the lung opens up new areas of basic and clinical asthma research. Open questions include: What are the asthma-specific alterations of resident, induced and infiltrating macrophage/ monocyte populations (studies to date have focused on broad populations of alveolar/airway macrophages and/or peripheral monocytes)? Do early life events associated with predisposition to subsequent development of asthma alter the macrophage development and landscape of the lungs and airways irrevocably and do these changes drive pathology? Can these various subtypes of macrophage be specifically targeted for therapeutic gain? What is the role of infiltrating monocytes in asthmatic airways inflammation in both stable and exacerbating phenotypes and what is the fate of macrophage/monocyte populations during periods of inflammatory resolution?

At present, a lack of bona fide markers for the distinction and isolation of these newly recognised various macrophage subsets is the biggest hindrance to the progress of research in this field; however, continued combination of macrophage fate mapping with "omics" approaches in the mouse may be expected to provide the tools to answer these questions. In the future, accurate macrophage phenotyping may play a role in the development of targeted personalised treatment programmes and could guide selection of optimal asthma therapies in the clinic.

\section{Acknowledgements}

The authors would like to thank Steven Maltby (University of Newcastle, New Lambton Heights, NSW, Australia) for providing valuable feedback during manuscript preparation.

\section{References}

1 Gibson PG, McDonald VM, Marks GB. Asthma in older adults. Lancet 2010; 376: 803-813.

2 Agusti A, Bel E, Thomas M, et al. Treatable traits: toward precision medicine of chronic airway diseases. Eur Respir J 2016; 47: 410-419.

3 Grainge CL, Maltby S, Gibson PG, et al. Targeted therapeutics for severe refractory asthma: monoclonal antibodies. Expert Rev Clin Pharmacol 2016; 9: 927-941.

4 Alexis NE. Biomarker sampling of the airways in asthma. Curr Opin Pulm Med 2014; 20: 46-52.

5 Simpson JL, Scott R, Boyle MJ, et al. Inflammatory subtypes in asthma: assessment and identification using induced sputum. Respirology 2006; 11: 54-61.

6 Gauthier M, Ray A, Wenzel SE. Evolving concepts of asthma. Am J Respir Crit Care Med 2015; 192: 660-668.

7 Fricker M, Heaney LG, Upham JW. Can biomarkers help us hit targets in difficult-to-treat asthma? Respirology 2017; 22: 430-442.

8 Green RH, Brightling CE, McKenna S, et al. Asthma exacerbations and sputum eosinophil counts: a randomised controlled trial. Lancet 2002; 360: 1715-1721.

$9 \quad$ Lumeng CN. Lung macrophage diversity and asthma. Ann Am Thorac Soc 2016; 13: Suppl. 1, S31-S34.

10 Ginhoux F, Guilliams M. Tissue-resident macrophage ontogeny and homeostasis. Immunity 2016; 44: 439-449.

11 Ginhoux F, Schultze JL, Murray PJ, et al. New insights into the multidimensional concept of macrophage ontogeny, activation and function. Nat Immunol 2016; 17: 34-40.

12 Yona S, Kim KW, Wolf $\mathrm{Y}$, et al. Fate mapping reveals origins and dynamics of monocytes and tissue macrophages under homeostasis. Immunity 2013; 38: 79-91. 
13 Jenkins SJ, Ruckerl D, Cook PC, et al. Local macrophage proliferation, rather than recruitment from the blood, is a signature of $\mathrm{T}_{\mathrm{H}} 2$ inflammation. Science 2011; 332: 1284-1288.

14 Schulz C, Gomez Perdiguero E, Chorro L, et al. A lineage of myeloid cells independent of Myb and hematopoietic stem cells. Science 2012; 336: 86-90.

15 Hashimoto D, Chow A, Noizat C, et al. Tissue-resident macrophages self-maintain locally throughout adult life with minimal contribution from circulating monocytes. Immunity 2013; 38: 792-804.

16 Scott CL, Henri S, Guilliams M. Mononuclear phagocytes of the intestine, the skin, and the lung. Immunol Rev 2014; 262: 9-24.

17 Gibbings SL, Goyal R, Desch AN, et al. Transcriptome analysis highlights the conserved difference between embryonic and postnatal-derived alveolar macrophages. Blood 2015; 126: 1357-1366.

18 Byrne AJ, Mathie SA, Gregory LG, et al. Pulmonary macrophages: key players in the innate defence of the airways. Thorax 2015; 70: 1189-1196.

19 Hussell T, Bell TJ. Alveolar macrophages: plasticity in a tissue-specific context. Nat Rev Immunol 2014; 14: 81-93.

20 Lee YG, Jeong JJ, Nyenhuis S, et al. Recruited alveolar macrophages, in response to airway epithelial-derived monocyte chemoattractant protein $1 / \mathrm{CCl} 2$, regulate airway inflammation and remodeling in allergic asthma. Am J Respir Cell Mol Biol 2015; 52: 772-784.

21 Murray PJ, Allen JE, Biswas SK, et al. Macrophage activation and polarization: nomenclature and experimental guidelines. Immunity 2014; 41: 14-20.

22 Xue J, Schmidt SV, Sander J, et al. Transcriptome-based network analysis reveals a spectrum model of human macrophage activation. Immunity 2014; 40: 274-288.

23 Tarique AA, Logan J, Thomas E, et al. Phenotypic, functional, and plasticity features of classical and alternatively activated human macrophages. Am J Respir Cell Mol Biol 2015; 53: 676-688.

24 Hilty M, Burke C, Pedro H, et al. Disordered microbial communities in asthmatic airways. PLoS One 2010; 5: e8578.

25 Wood LG, Simpson JL, Hansbro PM, et al. Potentially pathogenic bacteria cultured from the sputum of stable asthmatics are associated with increased 8-isoprostane and airway neutrophilia. Free Radic Res 2010; 44: 146-154. sputum. J Allergy Clin Immunol 2013; 131: 346-352.

27 Goleva E, Jackson LP, Harris JK, et al. The effects of airway microbiome on corticosteroid responsiveness in asthma. Am J Respir Crit Care Med 2013; 188: 1193-1201.

28 Simpson JL, Daly J, Baines KJ, et al. Airway dysbiosis: Haemophilus influenzae and Tropheryma in poorly controlled asthma. Eur Respir J 2016; 47: 792-800.

29 Liang Z, Zhang Q, Thomas CM, et al. Impaired macrophage phagocytosis of bacteria in severe asthma. Respir Res 2014; 15: 72.

30 Zetterlund A, Larsson PH, Muller-Suur C, et al. Budesonide but not terbutaline decreases phagocytosis in alveolar macrophages. Respir Med 1998; 92: 162-166.

31 Fitzpatrick AM, Teague WG, Burwell L, et al. Glutathione oxidation is associated with airway macrophage functional impairment in children with severe asthma. Pediatr Res 2011; 69: 154-159.

32 Fitzpatrick AM, Holguin F, Teague WG, et al. Alveolar macrophage phagocytosis is impaired in children with poorly controlled asthma. J Allergy Clin Immunol 2008; 121: 1372-1378.

33 Godard P, Chaintreuil J, Damon M, et al. Functional assessment of alveolar macrophages: comparison of cells from asthmatics and normal subjects. J Allergy Clin Immunol 1982; 70: 88-93.

34 da Silva-Martins CL, Couto SC, Muniz-Junqueira MI. Inhaled corticosteroid treatment for 6 months was not sufficient to normalize phagocytosis in asthmatic children. Clin Transl Allergy 2013; 3: 28.

35 Alexis NE, Soukup J, Nierkens S, et al. Association between airway hyperreactivity and bronchial macrophage dysfunction in individuals with mild asthma. Am J Physiol Lung Cell Mol Physiol 2001; 280: L369-L375.

36 Brugha RE, Mushtaq N, Round T, et al. Carbon in airway macrophages from children with asthma. Thorax 2014; 69: 654-659.

37 Kulkarni N, Pierse N, Rushton L, et al. Carbon in airway macrophages and lung function in children. $N$ Engl J Med 2006; 355: 21-30.

38 Watanabe T, Asai K, Fujimoto H, et al. Increased levels of HMGB-1 and endogenous secretory RAGE in induced sputum from asthmatic patients. Respir Med 2011; 105: 519-525.

39 Hou C, Zhao H, Liu L, et al. High mobility group protein B1 (HMGB1) in asthma: comparison of patients with chronic obstructive pulmonary disease and healthy controls. Mol Med 2011; 17: 807-815.

40 Cohen L, E X, Tarsi J, et al. Epithelial cell proliferation contributes to airway remodeling in severe asthma. Am J Respir Crit Care Med 2007; 176: 138-145.

41 Brown GC, Vilalta A, Fricker M. Phagoptosis - cell death by phagocytosis - plays central roles in physiology, host defense and pathology. Curr Mol Med 2015; 15: 842-851.

42 Simpson JL, Gibson PG, Yang IA, et al. Impaired macrophage phagocytosis in non-eosinophilic asthma. Clin Exp Allergy 2013; 43: 29-35.

43 Fernandez-Boyanapalli R, Goleva E, Kolakowski C, et al. Obesity impairs apoptotic cell clearance in asthma. J Allergy Clin Immunol 2013; 131: 1041-1047.

44 Huynh ML, Malcolm KC, Kotaru C, et al. Defective apoptotic cell phagocytosis attenuates prostaglandin $\mathrm{E}_{2}$ and 15-hydroxyeicosatetraenoic acid in severe asthma alveolar macrophages. Am J Respir Crit Care Med 2005; 172: 972-979.

45 Hoshi H, Ohno I, Honma M, et al. IL-5, IL-8 and GM-CSF immunostaining of sputum cells in bronchial asthma and chronic bronchitis. Clin Exp Allergy 1995; 25: 720-728.

46 Ackerman V, Marini M, Vittori E, et al. Detection of cytokines and their cell sources in bronchial biopsy specimens from asthmatic patients. Relationship to atopic status, symptoms, and level of airway hyperresponsiveness. Chest 1994; 105: 687-696.

47 Chanez P, Vignola AM, Paul-Eugene N, et al. Modulation by interleukin-4 of cytokine release from mononuclear phagocytes in asthma. J Allergy Clin Immunol 1994; 94: 997-1005. 

mononuclear phagocytes from allergic asthmatics after IgE-dependent stimulation. Am Rev Respir Dis 1992; 146: 768-774.

49 Catena E, Mazzarella G, Peluso GF, et al. Phenotypic features and secretory pattern of alveolar macrophages in atopic asthmatic patients. Monaldi Arch Chest Dis 1993; 48: 6-15.

50 Gosset P, Tillie-Leblond I, Oudin S, et al. Production of chemokines and proinflammatory and antiinflammatory cytokines by human alveolar macrophages activated by IgE receptors. J Allergy Clin Immunol 1999; 103: 289-297.

51 Tang C, Rolland JM, Ward C, et al. Modulatory effects of alveolar macrophages on CD4+ T-cell IL-5 responses correlate with IL-1beta, IL-6, and IL-12 production. Eur Respir J 1999; 14: 106-112.

52 Baines KJ, Simpson JL, Wood LG, et al. Transcriptional phenotypes of asthma defined by gene expression profiling of induced sputum samples. J Allergy Clin Immunol 2011; 127: 153-160.

53 Borish L, Mascali JJ, Dishuck J, et al. Detection of alveolar macrophage-derived IL-1 beta in asthma. Inhibition with corticosteroids. J Immunol 1992; 149: 3078-3082.

54 Simpson JL, Phipps S, Baines KJ, et al. Elevated expression of the NLRP3 inflammasome in neutrophilic asthma. Eur Respir J 2014; 43: 1067-1076.

55 Sousa AR, Lane SJ, Nakhosteen JA, et al. Expression of interleukin-1 beta (IL-1beta) and interleukin-1 receptor antagonist (IL-1ra) on asthmatic bronchial epithelium. Am J Respir Crit Care Med 1996; 154: 1061-1066.

56 Choy DF, Hart KM, Borthwick LA, et al. $\mathrm{T}_{\mathrm{H}} 2$ and $\mathrm{T}_{\mathrm{H}} 17$ inflammatory pathways are reciprocally regulated in asthma. Sci Transl Med 2015; 7: 301ra129.

57 Chesné J, Braza F, Mahay G, et al. IL-17 in severe asthma. Where do we stand? Am J Respir Crit Care Med 2014; 190: 1094-1101.

58 Song C, Luo L, Lei Z, et al. IL-17-producing alveolar macrophages mediate allergic lung inflammation related to asthma. I Immunol 2008; 181: 6117-6124.

59 Gosset P, Tsicopoulos A, Wallaert B, et al. Increased secretion of tumor necrosis factor alpha and interleukin-6 by alveolar macrophages consecutive to the development of the late asthmatic reaction. J Allergy Clin Immunol 1991; 88: 561-571

60 Tang C, Rolland JM, Li X, et al. Alveolar macrophages from atopic asthmatics, but not atopic nonasthmatics, enhance interleukin-5 production by CD4+ T cells. Am J Respir Crit Care Med 1998; 157: 1120-1126.

61 Borish L, Aarons A, Rumbyrt J, et al. Interleukin-10 regulation in normal subjects and patients with asthma. $J$ Allergy Clin Immunol 1996; 97: 1288-1296.

62 Robinson DS, Tsicopoulos A, Meng Q, et al. Increased interleukin-10 messenger RNA expression in atopic allergy and asthma. Am J Respir Cell Mol Biol 1996; 14: 113-117.

63 Zeibecoglou K, Ying S, Meng Q, et al. Macrophage subpopulations and macrophage-derived cytokines in sputum of atopic and nonatopic asthmatic subjects and atopic and normal control subjects. J Allergy Clin Immunol 2000; 106: 697-704.

64 Prieto J, Lensmar C, Roquet A, et al. Increased interleukin-13 mRNA expression in bronchoalveolar lavage cells of atopic patients with mild asthma after repeated low-dose allergen provocations. Respir Med 2000; 94: 806-814.

65 Lim S, Caramori G, Tomita K, et al. Differential expression of IL-10 receptor by epithelial cells and alveolar macrophages. Allergy 2004; 59: 505-514.

66 John M, Lim S, Seybold J, et al. Inhaled corticosteroids increase interleukin-10 but reduce macrophage inflammatory protein-1alpha, granulocyte-macrophage colony-stimulating factor, and interferon-gamma release from alveolar macrophages in asthma. Am J Respir Crit Care Med 1998; 157: 256-262.

67 Takanashi S, Hasegawa Y, Kanehira Y, et al. Interleukin-10 level in sputum is reduced in bronchial asthma, COPD and in smokers. Eur Respir J 1999; 14: 309-314.

68 Plummeridge MJ, Armstrong L, Birchall MA, et al. Reduced production of interleukin 12 by interferon gamma primed alveolar macrophages from atopic asthmatic subjects. Thorax 2000; 55: 842-847.

69 Redington AE, Madden J, Frew AJ, et al. Transforming growth factor-beta 1 in asthma. Measurement in bronchoalveolar lavage fluid. Am J Respir Crit Care Med 1997; 156: 642-647.

70 Vignola AM, Chanez P, Chiappara G, et al. Transforming growth factor-beta expression in mucosal biopsies in asthma and chronic bronchitis. Am J Respir Crit Care Med 1997; 156: 591-599.

71 Torrego A, Hew M, Oates T, et al. Expression and activation of TGF-beta isoforms in acute allergen-induced remodelling in asthma. Thorax 2007; 62: 307-313.

72 Planagumà A, Kazani $\mathrm{S}$, Marigowda $\mathrm{G}$, et al. Airway lipoxin $\mathrm{A}_{4}$ generation and lipoxin $\mathrm{A}_{4}$ receptor expression are decreased in severe asthma. Am J Respir Crit Care Med 2008; 178: 574-582.

73 Vachier I, Bonnans C, Chavis C, et al. Severe asthma is associated with a loss of LX, an endogenous anti-inflammatory compound. J Allergy Clin Immunol 2005; 115: 55-60.

74 Gagliardo R, Gras D, La Grutta S, et al. Airway lipoxin A /formyl peptide receptor 2-lipoxin receptor levels in pediatric patients with severe asthma. J Allergy Clin Immunol 2016; 137: 1796-1806.

75 Levy BD, Bonnans C, Silverman ES, et al. Diminished lipoxin biosynthesis in severe asthma. Am J Respir Crit Care Med 2005; 172: 824-830.

76 Ono E, Dutile S, Kazani S, et al. Lipoxin generation is related to soluble epoxide hydrolase activity in severe asthma. Am J Respir Crit Care Med 2014; 190: 886-897.

77 Kazani S, Planaguma A, Ono E, et al. Exhaled breath condensate eicosanoid levels associate with asthma and its severity. J Allergy Clin Immunol 2013; 132: 547-553.

78 Jiang Z, Zhu L. Update on the role of alternatively activated macrophages in asthma. J Asthma Allergy 2016; 9: 101-107.

79 Melgert BN, ten Hacken NH, Rutgers B, et al. More alternative activation of macrophages in lungs of asthmatic patients. J Allergy Clin Immunol 2011; 127: 831-833.

80 Girodet PO, Nguyen D, Mancini JD, et al. Alternative macrophage activation is increased in asthma. Am J Respir Cell Mol Biol 2016; 55: 467-475.

81 Becker M, De Bastiani MA, Parisi MM, et al. Integrated transcriptomics establish macrophage polarization signatures and have potential applications for clinical health and disease. Sci Rep 2015; 5: 13351.

82 Barnes PJ, Adcock IM. How do corticosteroids work in asthma? Ann Intern Med 2003; 139: 359-370. 
Barnes PJ. How corticosteroids control inflammation: Quintiles Prize Lecture 2005. Br J Pharmacol 2006; 148: 245-254.

Goleva E, Li LB, Eves PT, et al. Increased glucocorticoid receptor beta alters steroid response in glucocorticoid-insensitive asthma. Am J Respir Crit Care Med 2006; 173: 607-616.

Cosío BG, Mann B, Ito K, et al. Histone acetylase and deacetylase activity in alveolar macrophages and blood mononocytes in asthma. Am J Respir Crit Care Med 2004; 170: 141-147.

De Caterina R, Sicari R, Giannessi D, et al. Macrophage-specific eicosanoid synthesis inhibition and lipocortin-1 induction by glucocorticoids. J Appl Physiol 1993; 75: 2368-2375.

Wenzel SE, Trudeau JB, Westcott JY, et al. Single oral dose of prednisone decreases leukotriene $\mathrm{B}_{4}$ production by alveolar macrophages from patients with nocturnal asthma but not control subjects: relationship to changes in cellular influx and $\mathrm{FEV}_{1}$. J Allergy Clin Immunol 1994; 94: 870-881.

Dworski R, Fitzgerald GA, Oates JA, et al. Effect of oral prednisone on airway inflammatory mediators in atopic asthma. Am J Respir Crit Care Med 1994; 149: 953-959.

Linden M, Brattsand R. Effects of a corticosteroid, budesonide, on alveolar macrophage and blood monocyte secretion of cytokines: differential sensitivity of GM-CSF, IL-1 beta, and IL-6. Pulm Pharmacol 1994; 7: 43-47.

Ek A, Larsson K, Siljerud S, et al. Fluticasone and budesonide inhibit cytokine release in human lung epithelial cells and alveolar macrophages. Allergy 1999; 54: 691-699.

Maneechotesuwan K, Supawita S, Kasetsinsombat K, et al. Sputum indoleamine-2,3-dioxygenase activity is increased in asthmatic airways by using inhaled corticosteroids. J Allergy Clin Immunol 2008; 121: 43-50.

Duddridge M, Ward C, Hendrick DJ, et al. Changes in bronchoalveolar lavage inflammatory cells in asthmatic patients treated with high dose inhaled beclomethasone dipropionate. Eur Respir J 1993; 6: 489-497.

Harju T, Soini Y, Pääkkö R, et al. Up-regulation of heme oxygenase-I in alveolar macrophages of newly diagnosed asthmatics. Respir Med 2002; 96: 418-423.

Horváth I, Donnelly LE, Kiss A, et al. Raised levels of exhaled carbon monoxide are associated with an increased expression of heme oxygenase-1 in airway macrophages in asthma: a new marker of oxidative stress. Thorax 1998; 53: 668-672.

Lea S, Harbron C, Khan N, et al. Corticosteroid insensitive alveolar macrophages from asthma patients; synergistic interaction with a p38 mitogen-activated protein kinase (MAPK) inhibitor. Br J Clin Pharmacol 2015; 79: 756-766.

Bhavsar P, Hew M, Khorasani N, et al. Relative corticosteroid insensitivity of alveolar macrophages in severe asthma compared with non-severe asthma. Thorax 2008; 63: 784-790.

Bhavsar PK, Levy BD, Hew MJ, et al. Corticosteroid suppression of lipoxin $\mathrm{A}_{4}$ and leukotriene $\mathrm{B}_{4}$ from alveolar macrophages in severe asthma. Respir Res 2010; 11: 71.

Goleva E, Hauk PJ, Hall CF, et al. Corticosteroid-resistant asthma is associated with classical antimicrobial activation of airway macrophages. J Allergy Clin Immunol 2008; 122: 550-559.

Mercado N, Hakim A, Kobayashi Y, et al. Restoration of corticosteroid sensitivity by p38 mitogen activated protein kinase inhibition in peripheral blood mononuclear cells from severe asthma. PLoS One 2012; 7: e41582.

Bhavsar P, Khorasani N, Hew M, et al. Effect of p38 MAPK inhibition on corticosteroid suppression of cytokine release in severe asthma. Eur Respir J 2010; 35: 750-756.

Itkin IH, Menzel ML. The use of macrolide antibiotic substances in the treatment of asthma. J Allergy 1970; 45: $146-162$.

Cott GR, Cherniack RM. Steroids and "steroid-sparing” agents in asthma. N Engl J Med 1988; 318: 634-636.

Simpson JL, Powell H, Boyle MJ, et al. Clarithromycin targets neutrophilic airway inflammation in refractory asthma. Am J Respir Crit Care Med 2008; 177: 148-155.

Brusselle GG, Vanderstichele C, Jordens P, et al. Azithromycin for prevention of exacerbations in severe asthma (AZISAST): a multicentre randomised double-blind placebo-controlled trial. Thorax 2013; 68: 322-329.

Black PN, Blasi F, Jenkins CR, et al. Trial of roxithromycin in subjects with asthma and serological evidence of infection with Chlamydia pneumoniae. Am J Respir Crit Care Med 2001; 164: 536-541.

Kraft M, Cassell GH, Pak J, et al. Mycoplasma pneumoniae and Chlamydia pneumoniae in asthma: effect of clarithromycin. Chest 2002; 121: 1782-1788.

Sutherland ER, King TS, Icitovic N, et al. A trial of clarithromycin for the treatment of suboptimally controlled asthma. J Allergy Clin Immunol 2010; 126: 747-753.

Shoji T, Yoshida S, Sakamoto $\mathrm{H}$, et al. Anti-inflammatory effect of roxithromycin in patients with aspirin-intolerant asthma. Clin Exp Allergy 1999; 29: 950-956.

Sugawara A, Shima H, Sueki A, et al. Non-antibiotic 12-membered macrolides: design, synthesis and biological evaluation in a cigarette-smoking model. J Antibiot 2016; 69: 319-326.

Balloy V, Deveaux A, Lebeaux D, et al. Azithromycin anal
by LPS challenge. Br J Pharmacol 2014; 171: 1783-1794.

1 Ingram $\mathrm{K}$, Marker M, Meals $\mathrm{E}$, et al. Azithromycin inhibits macrophage tumor necrosis factor secretion in response to both azithromycin-susceptible and azithromycin-resistant pneumococci. J Pediatric Infect Dis Soc 2014; 3: 168-171.

12 Pascual A, Rodriguez-Baño J, Ballesta S, et al. Azithromycin uptake by tissue cultured epithelial cells. J Antimicrob Chemother 1997; 39: 293-295.

Hand WL, Boozer RM, King-Thompson NL. Antibiotic uptake by alveolar macrophages of smokers. Antimicrob Agents Chemother 1985; 27: 42-45.

Respir J 1990; 3: 886-890.

Aubert JD, Juillerat-Jeanneret L, Fioroni P, et al. Function of human alveolar macrophages after a 3-day course of azithromycin in healthy volunteers. Pulm Pharmacol Ther 1998; 11: 263-269.

Fonseca-Aten M, Okada PJ, Bowlware KL, et al. Effect of clarithromycin on cytokines and chemokines in children with an acute exacerbation of recurrent wheezing: a double-blind, randomized, placebo-controlled trial. Ann Allergy Asthma Immunol 2006; 97: 457-463.

11 Nakamura H, Fujishima S, Inoue T, et al. Clinical and immunoregulatory effects of roxithromycin therapy for chronic respiratory tract infection. Eur Respir J 1999; 13: 1371-1379. 
118 Kurdowska A, Noble JM, Griffith DE. The effect of azithromycin and clarithromycin on ex vivo interleukin-8 (IL-8) release from whole blood and IL-8 production by human alveolar macrophages. J Antimicrob Chemother 2001; 47: 867-870.

119 Kanoh S, Rubin BK. Mechanisms of action and clinical application of macrolides as immunomodulatory medications. Clin Microbiol Rev 2010; 23: 590-615.

120 Yamaryo T, Oishi K, Yoshimine $\mathrm{H}$, et al. Fourteen-member macrolides promote the phosphatidylserine receptor-dependent phagocytosis of apoptotic neutrophils by alveolar macrophages. Antimicrob Agents Chemother 2003; 47: 48-53.

121 Hodge S, Hodge G, Brozyna S, et al. Azithromycin increases phagocytosis of apoptotic bronchial epithelial cells by alveolar macrophages. Eur Respir J 2006; 28: 486-495.

122 Hodge S, Hodge G, Jersmann H, et al. Azithromycin improves macrophage phagocytic function and expression of mannose receptor in chronic obstructive pulmonary disease. Am J Respir Crit Care Med 2008; 178: 139-148.

123 Hodge S, Reynolds PN. Low-dose azithromycin improves phagocytosis of bacteria by both alveolar and monocyte-derived macrophages in chronic obstructive pulmonary disease subjects. Respirology 2012; 17: 802-807.

124 Taylor AE, Finney-Hayward TK, Quint JK, et al. Defective macrophage phagocytosis of bacteria in COPD. Eur Respir J 2010; 35: 1039-1047.

125 Huang CC, Chan WL, Chen YC, et al. Statin use in patients with asthma: a nationwide population-based study. Eur J Clin Invest 2011; 41: 507-512.

126 Zeki AA, Oldham J, Wilson M, et al. Statin use and asthma control in patients with severe asthma. BMJ Open 2013; 3: e003314.

127 Tse SM, Li L, Butler MG, et al. Statin exposure is associated with decreased asthma-related emergency department visits and oral corticosteroid use. Am J Respir Crit Care Med 2013; 188: 1076-1082.

128 Dunican EM, Fahy JV. The role of type 2 inflammation in the pathogenesis of asthma exacerbations. Ann Am Thorac Soc 2015; 12: Suppl. 2, S144-S149.

129 Maneechotesuwan K, Ekjiratrakul W, Kasetsinsombat K, et al. Statins enhance the anti-inflammatory effects of inhaled corticosteroids in asthmatic patients through increased induction of indoleamine 2,3-dioxygenase. $J$ Allergy Clin Immunol 2010; 126: 754-762.

130 Hothersall EJ, Chaudhuri R, McSharry C, et al. Effects of atorvastatin added to inhaled corticosteroids on lung function and sputum cell counts in atopic asthma. Thorax 2008; 63: 1070-1075.

131 Gao P, Gibson PG, Baines KJ, et al. Anti-inflammatory deficiencies in neutrophilic asthma: reduced galectin-3 and IL-1RA/IL-1beta. Respir Res 2015; 16: 5.

132 Thomson NC, Charron CE, Chaudhuri R, et al. Atorvastatin in combination with inhaled beclometasone modulates inflammatory sputum mediators in smokers with asthma. Pulm Pharmacol Ther 2015; 31: 1-8.

133 Morimoto K, Janssen WJ, Fessler MB, et al. Lovastatin enhances clearance of apoptotic cells (efferocytosis) with implications for chronic obstructive pulmonary disease. J Immunol 2006; 176: 7657-7665.

134 Wickert LE, Karta MR, Audhya A, et al. Simvastatin attenuates rhinovirus-induced interferon and CXCL10 secretion from monocytic cells in vitro. J Leukoc Biol 2014; 95: 951-959.

135 Sakamoto N, Hayashi S, Mukae H, et al. Effect of atorvastatin on $\mathrm{PM}_{10}$-induced cytokine production by human alveolar macrophages and bronchial epithelial cells. Int J Toxicol 2009; 28: 17-23.

136 Jin Y, Tachibana I, Takeda Y, et al. Statins decrease lung inflammation in mice by upregulating tetraspanin CD9 in macrophages. PLoS One 2013; 8: e73706.

137 Barnes PJ. Theophylline. Am J Respir Crit Care Med 2013; 188: 901-906.

138 Ito K, Lim S, Caramori G, et al. A molecular mechanism of action of theophylline: induction of histone deacetylase activity to decrease inflammatory gene expression. Proc Natl Acad Sci USA 2002; 99: 8921-8926.

139 Kraft M, Torvik JA, Trudeau JB, et al. Theophylline: potential antiinflammatory effects in nocturnal asthma. J Allergy Clin Immunol 1996; 97: 1242-1246.

140 Mascali JJ, Cvietusa P, Negri J, et al. Anti-inflammatory effects of theophylline: modulation of cytokine production. Ann Allergy Asthma Immunol 1996; 77: 34-38.

141 Dent G, Giembycz MA, Rabe KF, et al. Theophylline suppresses human alveolar macrophage respiratory burst through phosphodiesterase inhibition. Am J Respir Cell Mol Biol 1994; 10: 565-572.

142 Oliver B, Tomita K, Keller A, et al. Low-dose theophylline does not exert its anti-inflammatory effects in mild asthma through upregulation of interleukin-10 in alveolar macrophages. Allergy 2001; 56: 1087-1090.

143 Calhoun WJ, Stevens CA, Lambert SB. Modulation of superoxide production of alveolar macrophages and peripheral blood mononuclear cells by beta-agonists and theophylline. J Lab Clin Med 1991; 117: 514-522.

144 Banner KH, Page CP. Anti-inflammatory effects of theophylline and selective phosphodiesterase inhibitors. Clin Exp Allergy 1996; 26: Suppl. 2, 2-9.

145 Yao PL, Tsai MF, Lin YC, et al. Global expression profiling of theophylline response genes in macrophages: evidence of airway anti-inflammatory regulation. Respir Res 2005; 6: 89.

146 Rabe KF. Update on roflumilast, a phosphodiesterase 4 inhibitor for the treatment of chronic obstructive pulmonary disease. Br J Pharmacol 2011; 163: 53-67.

147 Bateman ED, Izquierdo JL, Harnest U, et al. Efficacy and safety of roflumilast in the treatment of asthma. Ann Allergy Asthma Immunol 2006; 96: 679-686.

148 Bousquet J, Aubier M, Sastre J, et al. Comparison of roflumilast, an oral anti-inflammatory, with beclomethasone dipropionate in the treatment of persistent asthma. Allergy 2006; 61: 72-78.

149 van Schalkwyk E, Strydom K, Williams Z, et al. Roflumilast, an oral, once-daily phosphodiesterase 4 inhibitor, attenuates allergen-induced asthmatic reactions. J Allergy Clin Immunol 2005; 116: 292-298.

150 Louw C, Williams Z, Venter L, et al. Roflumilast, a phosphodiesterase 4 inhibitor, reduces airway hyperresponsiveness after allergen challenge. Respiration 2007; 74: 411-417.

151 Gauvreau GM, Boulet LP, Schmid-Wirlitsch C, et al. Roflumilast attenuates allergen-induced inflammation in mild asthmatic subjects. Respir Res 2011; 12: 140.

152 Hohlfeld JM, Schoenfeld K, Lavae-Mokhtari M, et al. Roflumilast attenuates pulmonary inflammation upon segmental endotoxin challenge in healthy subjects: a randomized placebo-controlled trial. Pulm Pharmacol Ther 2008; 21: 616-623. 
153 Jin SL, Lan L, Zoudilova M, et al. Specific role of phosphodiesterase 4B in lipopolysaccharide-induced signaling in mouse macrophages. J Immunol 2005; 175: 1523-1531.

154 Buenestado A, Grassin-Delyle S, Guitard F, et al. Roflumilast inhibits the release of chemokines and TNF-alpha from human lung macrophages stimulated with lipopolysaccharide. Br J Pharmacol 2012; 165: 1877-1890.

155 Diamant Z, Mantzouranis E, Bjermer L. Montelukast in the treatment of asthma and beyond. Expert Rev Clin Immunol 2009; 5: 639-658.

156 Mao JT, Tsu IH, Dubinett SM, et al. Modulation of pulmonary leukotriene $\mathrm{B}_{4}$ production by cyclooxygenase-2 inhibitors and lipopolysaccharide. Clin Cancer Res 2004; 10: 6872-6878.

157 Thomet OA, Wiesmann UN, Schapowal A, et al. Role of petasin in the potential anti-inflammatory activity of a plant extract of Petasites hybridus. Biochem Pharmacol 2001; 61: 1041-1047.

158 Brock TG, McNish RW, Peters-Golden M. Capacity for repeatable leukotriene generation after transient stimulation of mast cells and macrophages. Biochem J 1998; 329: 519-525.

159 Hasday JD, Meltzer SS, Moore WC, et al. Anti-inflammatory effects of zileuton in a subpopulation of allergic asthmatics. Am J Respir Crit Care Med 2000; 161: 1229-1236.

160 Can M, Yüksel B, Demirtas S, et al. The effect of montelukast on soluble interleukin-2 receptor and tumor necrosis factor alpha in pediatric asthma. Allergy Asthma Proc 2006; 27: 383-386.

161 Theron AJ, Steel HC, Tintinger GR, et al. Cysteinyl leukotriene receptor-1 antagonists as modulators of innate immune cell function. J Immunol Res 2014; 2014: 608930.

162 Lin YC, Huang MY, Lee MS, et al. Effects of montelukast on M2-related cytokine and chemokine in M2 macrophages. J Microbiol Immunol Infect 2016; in press [http://dx.doi.org/10.1016/j.jmii.2016.04.005].

163 Ferracini M, Martins JO, Campos MR, et al. Impaired phagocytosis by alveolar macrophages from diabetic rats is related to the deficient coupling of LTs to the Fc $\gamma \mathrm{R}$ signaling cascade. Mol Immunol 2010; 47: 1974-1980.

164 Johnston SL, Edwards MR. Mechanisms of adverse effects of $\beta$-agonists in asthma. Thorax 2009; 64: 739-741.

165 Barnes PJ. Scientific rationale for inhaled combination therapy with long-acting $\beta_{2}$-agonists and corticosteroids. Eur Respir J 2002; 19: 182-191

166 Barnes PJ. Effect of beta-agonists on inflammatory cells. J Allergy Clin Immunol 1999; 104: S10-S17.

167 Liggett SB. Identification and characterization of a homogeneous population of $\beta_{2}$-adrenergic receptors on human alveolar macrophages. Am Rev Respir Dis 1989; 139: 552-555.

168 Turki J, Green SA, Newman KB, et al. Human lung cell $\beta_{2}$-adrenergic receptors desensitize in response to in vivo administered beta-agonist. Am J Physiol 1995; 269: L709-L714.

169 Casale TB, Wood D, Wescott S, et al. Immunohistochemical identification of lung cells responsive to beta-stimulation with a rise in cAMP. J Appl Physiol 1987; 63: 434-439.

170 Kelsen SG, Aksoy MO, Brennan K, et al. Chronic effects of inhaled albuterol on beta-adrenoceptor system function in human respiratory cells. J Asthma 2000; 37: 361-370.

171 Zetterlund A, Hjemdahl P, Larsson K. $\beta_{2}$-Adrenoceptor desensitization in human alveolar macrophages induced by inhaled terbutaline in vivo is not counteracted by budesonide. Clin Sci 2001; 100: 451-457.

172 Fuller RW, O’Malley G, Baker AJ, et al. Human alveolar macrophage activation: inhibition by forskolin but not beta-adrenoceptor stimulation or phosphodiesterase inhibition. Pulm Pharmacol 1988; 1: 101-106.

173 Pacheco Y, Hosni R, Chabannes B, et al. Leukotriene $\mathrm{B}_{4}$ level in stimulated blood neutrophils and alveolar macrophages from healthy and asthmatic subjects. Effect of beta-2 agonist therapy. Eur J Clin Invest 1992; 22: 732-739.

174 Menzies D, Nair A, Meldrum KT, et al. Simvastatin does not exhibit therapeutic anti-inflammatory effects in asthma. J Allergy Clin Immunol 2007; 119: 328-335.

175 Cowan DC, Cowan JO, Palmay R, et al. Simvastatin in the treatment of asthma: lack of steroid-sparing effect. Thorax 2010; 65: 891-896.

176 Braganza G, Chaudhuri R, McSharry C, et al. Effects of short-term treatment with atorvastatin in smokers with asthma - a randomized controlled trial. BMC Pulm Med 2011; 11: 16.

177 Sullivan P, Bekir S, Jaffar Z, et al. Anti-inflammatory effects of low-dose oral theophylline in atopic asthma. Lancet 1994; 343: 1006-1008.

178 Lim S, Tomita K, Caramori G, et al. Low-dose theophylline reduces eosinophilic inflammation but not exhaled nitric oxide in mild asthma. Am J Respir Crit Care Med 2001; 164: 273-276.

179 Kidney J, Dominguez M, Taylor PM, et al. Immunomodulation by theophylline in asthma. Demonstration by withdrawal of therapy. Am J Respir Crit Care Med 1995; 151: 1907-1914. 